\title{
Concerning the Mechanism of the Decaying of Typhoon
}

\author{
By Misuzu Wada \\ Meteorological Research Institute, Tokyo \\ (Manuscript received 28 March 1968, in revised form 13 June 1969)
}

\begin{abstract}
A quantitative analysis is made to investigate the mechanism of decaying of a tropical cyclone using the data of typhoon "Tilda" (6123).

During the decaying stage of the typhoon, thermal structure of warm core at the upper layer is considerably modified. On the other hand the amount of released latent heat estimated for an air column enclosing the typhoon and extending from the surface to the top of the storm much decreases. So, this modification of the thermal field seems to be closely related to the change of activity of cumulonimbus convection within the typhoon region.

It is the main purpose of the present analysis to clarify the relation between the change of the activity of convection within the typhoon region and that of warm core thermal field. For this purpose, we make a budget calculation of heat and water vapor, using the first law of thermodynamics and the continuity relation of water vapor respectively, and show that the convective transport of heat and water vapor, which has played an important role during the mature stage, weakens considerably as the typhoon decays.

The later part of the analysis is devoted to determine the vertical distribution of liberation of latent heat. It is shown that the liberation of latent heat at the upper layer decreases remarkably as the thermal field is modified. This suggests that the diminution of high cumulonimbus towers which are the main source of released latent heat at the upper layer, plays an essential role on the destruction of the warm core thermal structure of the typhoon.

Finally it is shown that the activity of high cumulonimbus towers is controlled by moisture supply in the lower layer.
\end{abstract}

\section{Introduction}

After tropical cyclones move over land, they usually weaken rapidly. It was usually considered that the increased friction is the primary cause for the decay of tropical cyclones after landing. However, Hubert (1955) attempted to determine the effect of friction on the rate of filling after a hurricane passes from water to land surface, and he concluded that friction alone is not enough to account for the filling over land and that the decrease in energy supply is the dominant factor which causes the filling over land. Palmén (1958) gave some quantitative discussion on the problem of the transformation of a tropical cyclone into an extratropical cyclone and showed that the fricitional dissipation of kinetic energy over land is smaller by one order than the production of that in a cyclone region and the significant part of kinetic energy produced by the liberation of potential energy is exported from the region of cyclonic disturbance into westerly zone. However, his treatment was cencerned with rather large domain enclosing the tropical cyclone in it. Yanai (1958) made a budget calculation of a typhoon during its decaying stage. His analysis showed thermal structure changes from the symmetric to the asymmetric configuration. This transformation in the thermal field was accompanied with the change in the production of kinetic energy. Hence, he pointed out that it is necessary to clarify the mechanism of maintenance of warm core. Miller (1964) attempted to calculate kinetic energy budget of a hurricane when it approached to and landed on the Florida Peninsula. He compared the energy budget of the hurricane over land with that over the ocean. His computation indicated that the reduction of the rate of kinetic energy production is more considerable than the increase of surface frictional dissipation after landing, and he pointed out the important role of energy supply in the lower layer to maintain the tropical cyclone.

It is well known that the tropical cyclone is a thermally driven circulation. One of the most essential characteristics of the thermal structure of 
the tropical cyclone is the existence of the warm core; temperature increases toward cyclone center. The mean vertical structure of the circulation in the tropical cyclone. is that the inflow layer exists under about the $700 \mathrm{mb}$ level and the outflow in the upper layer above the $400 \mathrm{mb}$ level compensates the inflow in the lower layer. The middle layer from the $700 \mathrm{mb}$ level to the 400 $\mathrm{mb}$ level is considered to be nearly non-divergent (Riehl, 1954; and Palmén and Riehl, 1957).

The combined structure of the thermal field and circulation mentioned above plays a significant role on the mechanism of kinetic energy production in the tropical cyclone. The main source of kinetic energy in the tropical cyclone is the release of potential energy due to the ascent of air in the warm core and the descent in the cooler surroundings. Thus, kinetic energy is produced only when the temperature field is of warm core type.

It is also known that the warm core outside of the eye is maintained mostly by the release of latent heat of condensation in the rising air from the surface. A detailed analysis of a formative typhoon by Yanai (1961) revealed the process of the creation of the warm core. He made a budget calculation of heat and moisture during the formative stage, and identified the source of heat for the warming with the released latent heat of condensation. Yanai $(1961,1963)$ further inferred the important role of small-scal penetrative cumulonimbus towers on the upward transport of heat from the analysis of the first formation of warm core at the upper troposphere. Riehl and Malkus (1958, 1961) put forward the "hot tower hypothesis" They considered that the ascent in the rain area occurs in extremely restricted region of undiluted cumulonimbus towers, and the latent heat is released not uniformly throughout the rain area but in a concentrated manner in spiral convective bands of narrow width especially in a central ring surrounding the eye. Since a radial gradient of temperature field is essential for the production of kinetic energy of the tropical cyclone, it is expected that the destruction of warm core has a significant effect upon the decaying of the typhoon (Yanai, 1958).

In the present anaysis, it is shown that clear destruction of the warm core occures in the upper layer after landing of a typhoon. It is considered that the heat supply from the warm ocean surface and the moisture supply through the inflow layer are primarily responsible for the maintenance of the warm core through the active cumulonimbus towers. Therefore, the decrease in both these supplies after landing causes the activity of convection within the typhoon region to weaken.

The major purpose of the present analysis is to investigate the relation between the change in thermal structure of the typhoon and activity of cumulus convection within it and hence to clarify the mechanism of the decay of a typhoon over land.

\section{Synoptic situation of typhoon "Tilda"}

The present analysis is based on the data obtained in the vicinity of Typhoon "Tilda" of October 1961. Tilda was selected because the center of the typhoon passed through the Okinawa islands so that the upper sounding data over the oceanic area were available.

Moreover as it landed on China mainland where a dense rawinsonde observation network exists, it was possible to compare the feature of the typhoon over the land with that over the ocean. Another advantage in using Tilda's data is in the fact that the thermal structure in its environment remained almost unchanged during the period of the present analysis and the modifica-

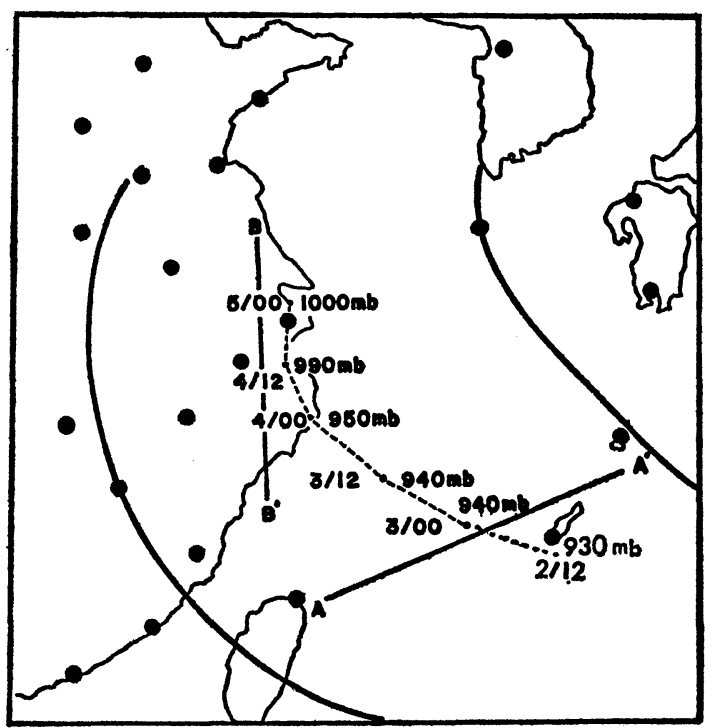

Fig. 1 Dashed line indicates track of typhoon "Tilda" (6123). Solid lines A-A' and B-B' correspond to the location of the cross secsion Fig. 3 and 4 respectively. are raob stations. Thick solid lines indicate the region of the present analysis. 


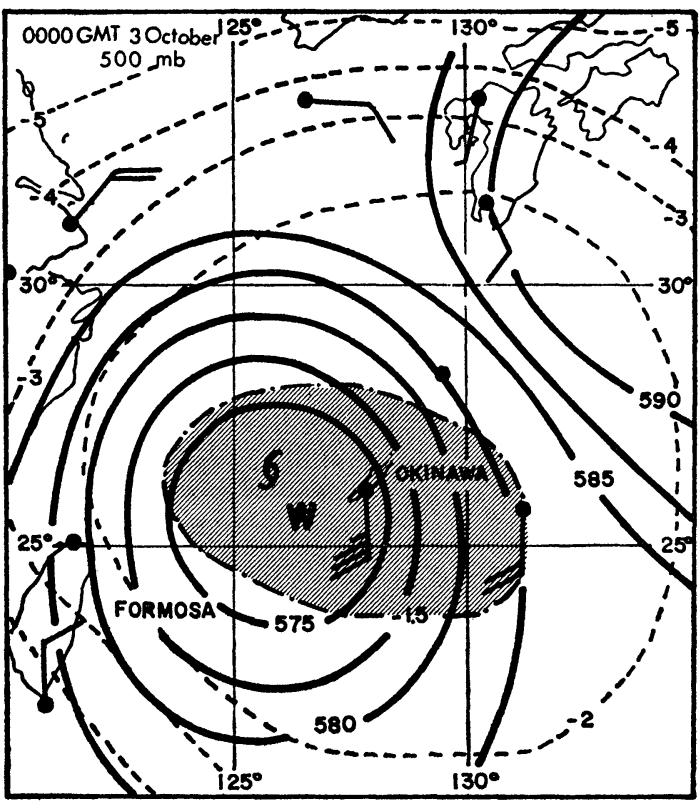

Fig. 2 a 500-mb 0000 GMT 3 October 1961. Solid lines denotes contour lines and dashed lines is isotherms.

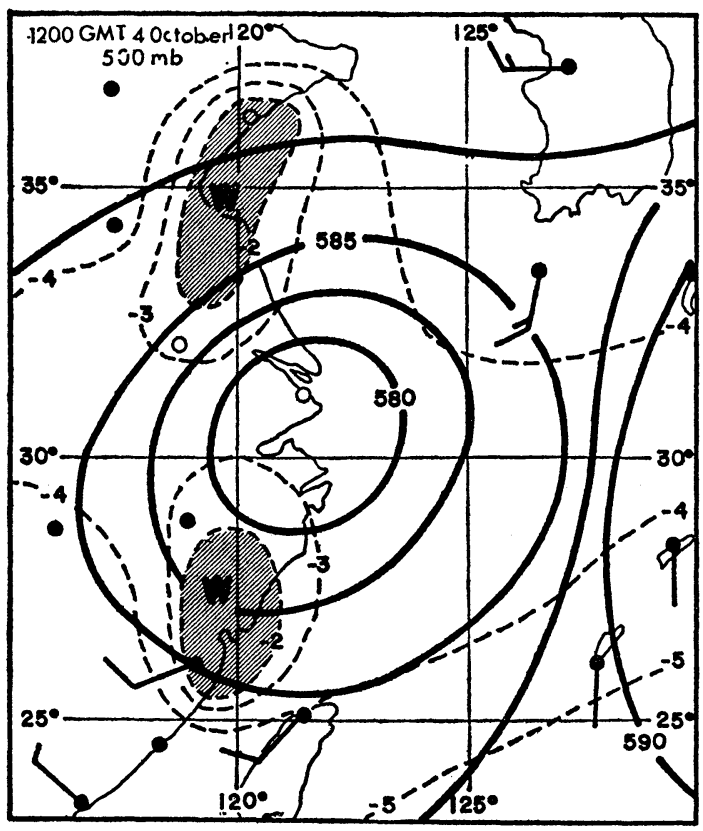

Fig. 2 b 500-mb 1200 GMT 4 October 1961

tion of thermal structure of the typhoon appeared very clearly.

After reaching the mature stage, typhoon "Tilda" moved over the East China Sea heading for the China mainland. Tilda landed at the east coast on the 4th of October 1961. Successive position of the center and the central sea-level pressure

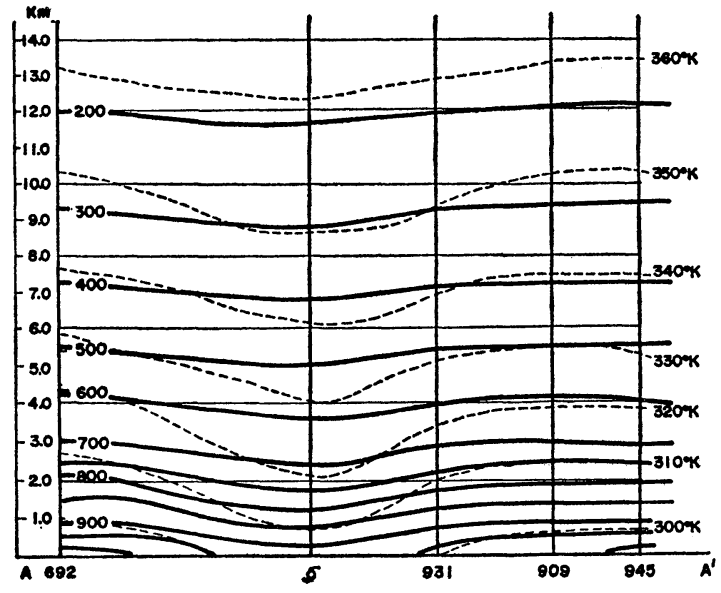

Fig. 3 a vertical cross section 0000 GMT 3 October along the line shown in Fig. 1 by $A-A^{\prime}$. Solid line are the isobar (mb), dashed line isentropes $\left({ }^{\circ} \mathrm{K}\right)$

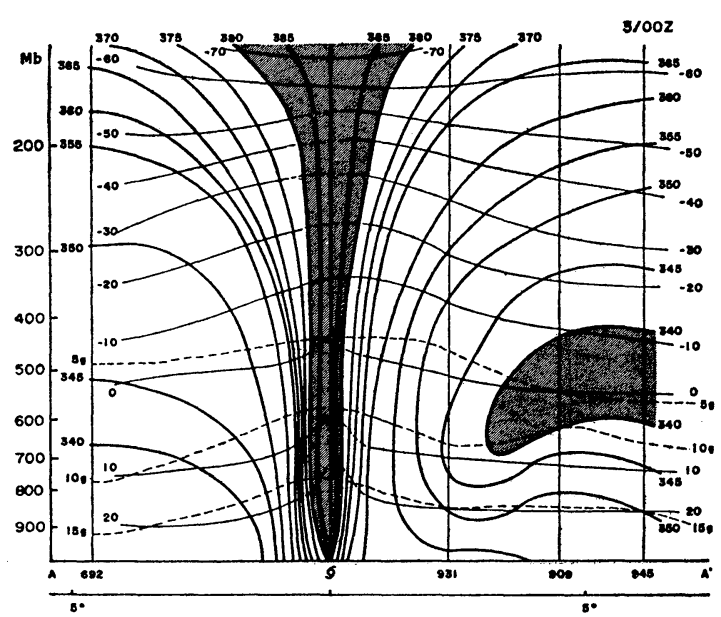

Fig. $3 \mathrm{~b}$ Vertical section 0000 GMT 3 October (same time with $3 \mathrm{a}$ ). solid limes indicate the isolines of equivalent potential temperature $(K)$, thin solid lines isotherms, dashed lines isolines of mixing ratio.

are shown in Fig. 1. The upper air observation stations are indicated in this figure.

Synoptic analysis is made three hourly for the surface and twelve hourly for the pressure levels $1000,850,700,500,400,300,200$ and $100 \mathrm{mb}$ from 1200 GMT 2 October to 1200 GMT 5 October 1961. Some of them are reproduced in the following.

On the 3rd of October when the typhoon was nearly in a mature stage, a clear thermal structure with warm core existed in the upper layer especially in the 500-200 mb layer (Fig. 2 a). However, 


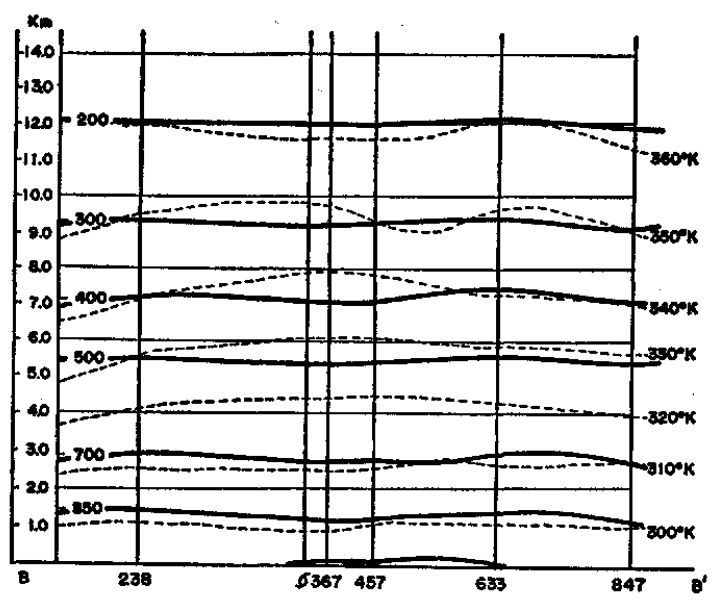

Fig. 4 a Vertical cross section 0000 GMT 5 October, along the line shown in Fig. 1 by $\mathbf{B - B}$. Symbol as in Fig. 3 a.

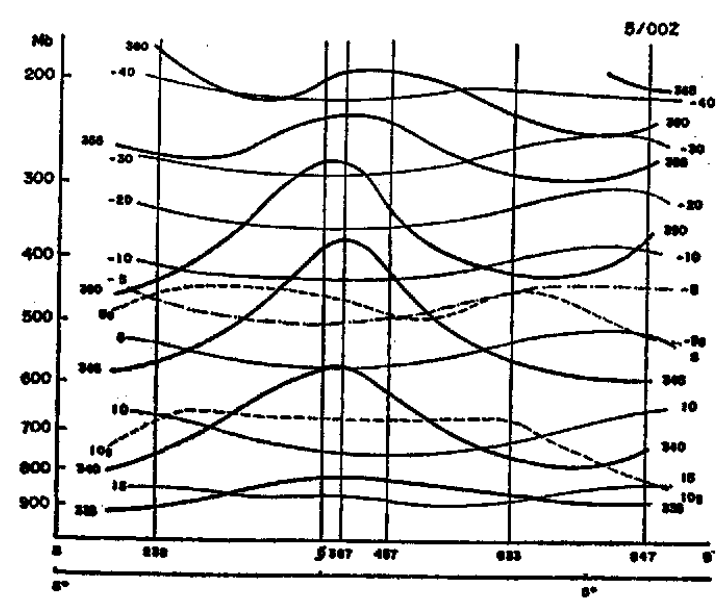

Fig. 4 b Vertical cross section 0000 GMT 5 October (same time with $4 \mathrm{a}$ ). Symbol as in Fig. $3 \mathbf{b}$.

as the typhoon decayed, the warm core began to dissipate. On the 4 the of October, the core was seen dissipated completly and two weak temperature maxima were recognized (Fig. $2 \mathrm{~b}$ ). As is seen in these maps, the decrease of horizontal size and of the temperature of the warm core were observed as the typhoon moved northward.

Fig. $3 \mathrm{a}$ and $3 \mathrm{~b}$ represent the vertical structure of the typhoon in the mature stage (00 GMT 3 October) and Fig. $4 \mathrm{a}$ and $4 \mathrm{~b}$ in the decaying stage (00 GMT 5 October). The location of the vetical cross section used for Fig. 3 and 4 are illustrated in Fig. 1 by solid lines $\mathbf{A}-\mathbf{A}^{\prime}$ and $\mathbf{B}-\mathbf{B}^{\prime}$ respectively. The vertical distributions of pressure and potential temperature are shown in Fig. 3 a and $4 \mathrm{a}$ and those of temperature, specific humidity and equivalent potential temperature in Fig. $3 \mathrm{~b}$ and $4 \mathrm{~b}$.

The temperature distribution in the mature stage looks nearly axially symmetric (Fig. 3 a). Fruthermore, we can see a chmney-like distribution of high equivalent potential temperature in the central region (Fig. $3 \mathrm{~b}$ ). This distribution is explained by the ascent of warm and moist air form the surface to the upper levels. An inversion of the equivalent potential temperature is recognized at the right side of Fig. $3 \mathrm{~b}$.

We could not recognize any significant change in the thermal filed between 12 GMT 3 October and 00 GMT 4 October in the present synoptic analysis. However, the thermal sturcture changed considerably between 12 GMT 4 October and 00 GMT 5 October. At this stage we can no longer recognize the symmetric temperature distribution. In the cross section for the stage (00 GMT 5 October), it is shown that a cold air occupies the central region (Fig. 4 a). As shown in Fig. $4 \mathrm{~b}$, equivalent potential temperature increases with hight and the inversion that existed previously (Fig. $3 \mathrm{~b}$ ) has disappered. The stratification has been stabilized in this stage.

In order to show the situation of the destruction of the warm core more clearly, we show in Fig. 5 the time change of anomalous space-mean temperature within the circular area of $3 \mathrm{deg}$ latitude radius from the average value of spacemean temperature within the same circular area

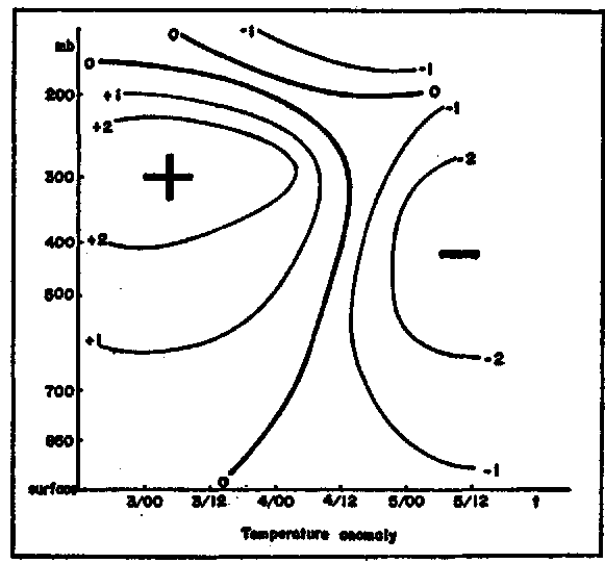

Fig. 5 Vertical time section of the anomary of mean temperature within 3 -deg. radius from the average value between 0000 GMT 3 october and 0000 GMT 5 October. 
for the three days under consideration.

According to the analysis of mean virtural temperature between the $500 \mathrm{mb}$ and the $200 \mathrm{mb}$ levels, the cooling is found as much as $3^{\circ} \mathrm{C}$ in the central region, while the warming of about $0.8^{\circ} \mathrm{C}$ is observed at about $400 \mathrm{~km}$ outside of the center during the period from 00 GMT 4 October to 00 GMT 5 October. These two facts are consistent with a rise of the central surface pressure about $40 \mathrm{mb}$ and a slight fall of the surface pressure at about $400 \mathrm{~km}$ outside of the center. Similar facts were pointed out by Miller (1964) and Kasahara (1953). Kasahara intended to explain these phenomena theoretically by his pivot theory. These facts seem to suggest that the destruction of the warm core is not caused by the advection of cold air in the upper layer, but is caused from the weakening of convective activity within the typhoon.

\section{The mass balance}

We made a quantitative analysis for three days (00 GMT 3 to 12 GMT 5 October) using all available data including those from reconnaisance flight.

In the following analysis, we use a cylindrical coordinate system which has the origin at the center of the typhoon and moves with the center. We determine the flux of any property through a cylindrical wall whose radius is about $500 \mathrm{~km}$ (5-deg. latitude). This radius is only one common radius for which the mass flow can be accurately determined from the surface to the $100 \mathrm{mb}$ level for these three days.

Along the wall of the column all properties such as resultant wind, specific humidity, temperature and pressure obtained every $22.5^{\circ}$ of azimuth angle for the surface and $45.0^{\circ}$ for the upper levels. These meteorological element were determind only by the interpolation or extrapolation method, and the composit technich was not used because our mine purpose are concerning to abrupt change of the typhoon.

As a first step in the flux caluculation, mass balance must be computed. For this purpose it shoud be noted that even in a strong deepening cyclone, the change of mass inside a given cylinder is so small that it is within the range of error of the wind measurement. As an example, we will consider a very extremely case where the surface pressure changes $40 \mathrm{mb}$ per 12 hour for an entire circular area within 5-deg. latitude radius. This corresponds to only a small amount of inflow of about $0.4 \mathrm{~m} / \mathrm{sec}$ at the radius from surface to the $500 \mathrm{mb}$ level. Actually pressure change is much smaller than this. So this assumption is quite reasonable. Thus in an analysis of tropical cyclone it may be assumed

$$
\int_{P_{t}}^{P_{0}} \phi v_{r} r d \theta d P=0
$$

where $p_{0}$ is the surface pressure, which is assumed here to be $100 \mathrm{mb}, p_{t}$ is the pressure at the top of the cyclone $(100 \mathrm{mb}), v_{r}$ is the radial component of wind velocity, $r$ is the radius, and $\theta$ is the azimuth angle, measured counter clockwise.

The wind data are quite sparse at upper levels, especially at $100 \mathrm{mb}$ and $200 \mathrm{mb}$. So the wind field at the upper level $(100 \mathrm{mb})$ was adjusted so as to satisfy (3.1) and to achive the mass balance. Here, the adjustment was made only with respect to speed but not to direction for the sake of simplicity. The corection needed in the adjustment is about ten percent of the uncorrected wind data.

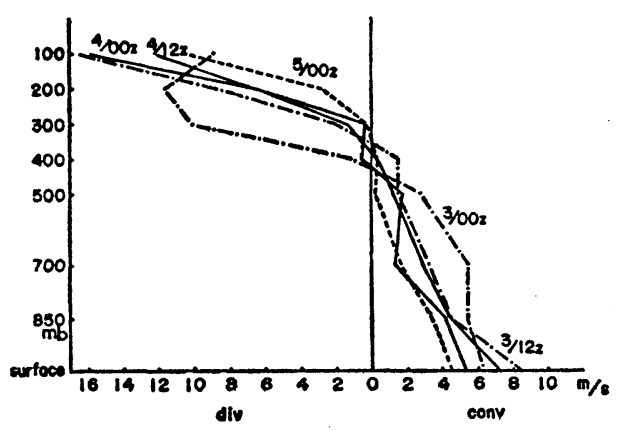

Fig. 6 Vertical profiles of mean radial wind within a circle of 5-deg radius. Numerals beside lines denote dating.

Fig. 6 shows that the inflow into the typhoon takes place mainly below the $700 \mathrm{mb}$ level, and the outflow above the $400 \mathrm{mb}$ level. This feature is typical of tropical cyclones (c. f. Jordan, 1952; Miller, 1958; Izawa, 1964).

Using the mass flow thus estimated, the mean vertical motion within the column is obtained by successive addition of the horizontal divergence based on the continuity relation;

$$
\omega_{n}=\sum_{m=1}^{n} \frac{D_{m-1}+D_{m}}{2}\left(p_{m-1}-p_{m}\right)
$$

where $\omega$ is vertical $p$-velocity, and subscript $m$ 


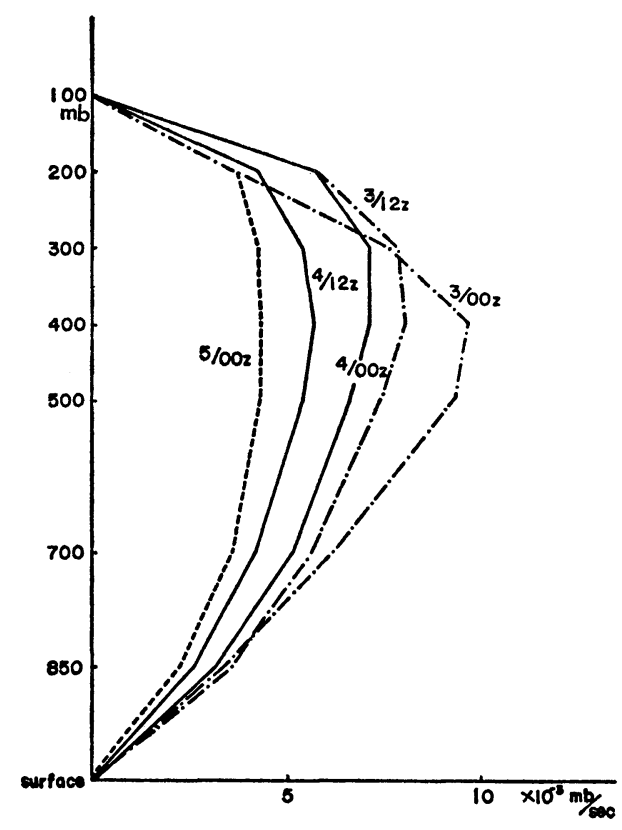

Fig. 7 Vertical profile of the mean vertical $p$-velocity within a circle of 5-deg radius. Numerals beside lines denote dating.

and $n$ denote the value at standarded pressure level. Here it is assueed that the vertical $p$ velocity is zero at the $1000 \mathrm{mb}$ level. The mean vertical $p$-velocity thus obtained are shown in Fig. 7.

\section{The estimation of drag coefficient}

In order to estimate the surface drag coefficient, we make a calculation of angular momentum budget of the typhoon in the same manner as Palmén and Riehl (1957) did. On the 3rd of October, Tilda was nearly in the steady state. Hence, composite data for 36 hours (from 00 GMT 2 October to 00 GMT 3 October) gives a reasonably accurate picture of the cyclone.

The absolute angular momentum $M$ is expressed in the form

$$
M=v_{\theta} r+\frac{1}{2} f r^{2}
$$

in the cylindrical coordinate system with an origin at the typhoon center, where $v_{\theta}$ is tangential wind component, $f$ is Coriolis factor. Omitting lateral stress, the momentum equation is given by

$$
\rho \frac{d M}{d t}=\rho \frac{d}{d t}\left(v_{\theta} r+\frac{1}{2} f r^{2}\right)
$$

$$
=-\frac{\partial p}{\partial \theta}+r \frac{\partial \tau_{\theta z}}{\partial z}
$$

Here $\rho$ is the air density and $\tau_{\theta z}$ is the tangential component of shearing stress. Integrating (4.2) over the cylindrical volume under the assumption of steady state,

$$
\frac{2 \pi}{g} \int_{P_{t}}^{P_{0}} \overline{M v_{r}} r d p=2 \pi \int_{P_{b}}^{P_{0}} r^{2} \bar{\tau}_{\theta 0} d r
$$

where the bar denotes the average along the circle with radius $r, \tau_{\theta 0}$ is the tangential component of shearing stress at the surface. Here the advection term has been transformed to a surface integral over the boundary surface and it is assumed that the stress at the top of the storm vanishes, and that the vertical $p$-velocity vanishes both at the surface level and at the top of the storm. Thus the equation (4.3) means that the net convergence of momentum in the cylinder extending from the surface to the top of the storm must be equal to the eddy transport of momentum to the surface for the steady state.

Dividing the momentum transport across the lateral boundary of a cylinder with radius $r$ into two parts, one due to the mean meridional motion and the other due to the eddy motion, we get

$$
\begin{gathered}
\int_{10,0}^{1000} \overline{\left(v_{\theta} r+\frac{1}{2} f r^{2}\right) v_{r} r} d p=\int_{100}^{1000} \bar{v}_{\theta} \bar{v}_{r} r^{2} d p \\
+\int_{100}^{1000} \overline{v_{\theta}^{\prime} v_{r}^{\prime}} r^{2} d p+\frac{1}{2} \int f r^{3} \bar{v}_{r} d p
\end{gathered}
$$

where the prime denotes the deviation from the average value. Here the third term of (4.4), transport of the earth's angular momentum due to mean meridional motion, makes no contribution to the net balance since no net mass flow takes place through the cylinder. Thus,

$$
\int_{0}^{r_{1}} \bar{\tau}_{\theta 0} r^{2} d r=\frac{r_{1}^{2}}{g}\left[\int_{100}^{1000}\left(\bar{v}_{\theta} \bar{v}_{r}+\overline{v_{\theta}^{\prime} v_{r}}\right) d p\right]_{r=r_{1}}
$$

and

$$
\begin{aligned}
\int_{r_{1}}^{r_{2}} \bar{\tau}_{\theta 0} r^{2} d r= & \frac{r_{2}^{2}}{g}\left[\int\left(\bar{v}_{\theta} \bar{v}_{r}+\overline{v_{\theta}^{\prime} v_{r}^{\prime}}\right) d p\right]_{r=r_{2}} \\
& -\frac{r_{1}^{2}}{g}\left[\int\left(\bar{v}_{\theta} \bar{v}_{r}+\overline{v_{\theta}^{\prime} v_{r}^{\prime}}\right) d p\right]_{r=r_{1}}
\end{aligned}
$$

where $g$ is acceleration of gravity. We take $r_{1}$ 


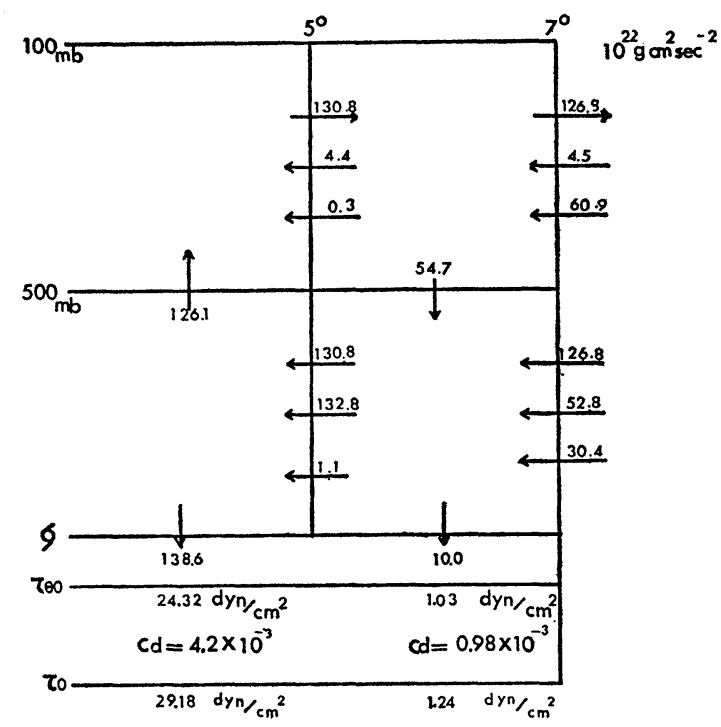

Fig. 8 Angular momentum budget diagram $\left(10^{22} \mathrm{~g}\right.$ $\mathrm{cm}^{2} \mathrm{sec}^{-2}$ ). Horizontal arrows denote flow across radii in each layer; upper arrows give transport due to earth's rotation, middle arrows that due to mean motion and lower arrows that due to eddy motion. Downward arrows at the bottom show momentum transport to the surface and the arrows at the $500 \mathrm{mb}$ level show the momentum transport through this level. Surface tangential stress $\left(\tau_{\theta_{0}}\right)$ and surface stress $\left(\tau_{0}\right)$ are given below this diagram. $C_{d}$ is drag coefficient.

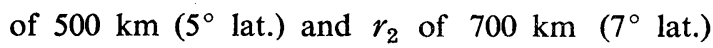
and make the budget calculation for the following two parts using (4.5) and (4.6) respectively: the inner part is the cylinder with radius $r_{1}$ and the outer part is the annular column between the radii $r_{2}$ and $r_{1}$. Angular momentum transports are shown in Fig. 8. In this diagram, the upper horizontal arrows represent the transports of earth's angular momentum due to the mean meridional motion, the middle horizontal arrows momentum transports due to the the mean motion and the lower horizontal arrows the eddy transports. The value of surface tangential stress thus obtained, are shown in the lower part of the diagram. The value for the inner region is $24.32 \mathrm{dyne} / \mathrm{cm}^{2}$ and that for the outer region $1.03 \mathrm{dyne} / \mathrm{cm}^{2}$, while the mean surface wind velocity for the inner region is $28.6 \mathrm{~m} / \mathrm{sec}$ and that for the outer region 7.5 $\mathrm{m} / \mathrm{sec}$.

Using the well known empirical law,

$$
\tau_{\theta 0}=\rho C_{d} \boldsymbol{V}_{\theta 0}\left|\boldsymbol{V}_{0}\right|
$$

we can estimate the drag coefficient $C_{d}$. Here $V_{0}$ is the surface wind and $V_{\theta 0}$ is tangential component of the wind. The results are $4.2 \times 10^{-3}$ for the inner region, $0.98 \times 10^{-3}$ for the outer region.

Sverdrup (1957) summarized available estimation of $C_{i l}$ over water. Although its distribution is scattering estimated value of $C_{d}$ indicates a sort of parabolic distribution with $C_{d}$ reaching a minimum at wind speed of $6 \mathrm{~m} / \mathrm{sec}$, then gradually increasing to about $3.3 \times 10^{-3}$ at wind speed of $25 \mathrm{~m} / \mathrm{sec}$. Wilson (1960) collected estimations from 46 different source and attempted to adjust all value of $C_{d}$ to a standard height of $10 \mathrm{~m} . \mathrm{He}$ concluded that for strong wind $(>10 \mathrm{~m} / \mathrm{sec}$, mean about $20 \mathrm{~m} / \mathrm{sec}$ ) the mean value of $C_{d}$ is $2.37 \times$ $10^{-3}$ with standard deviation of $0.56 \times 10^{-3}$, while for light wind $(<10 \mathrm{~m} / \mathrm{sec}$, mean about $5 \mathrm{~m} / \mathrm{sec})$ the value of $C_{d}$ is widely scattered and the average value is $1.49 \times 10^{-3}$ with standard deviation of $0.83 \times 10^{-3}$.

For very strong wind such as in the typhoon, there is little knoledge on the value of the drag coefficient. Using the data for the mean hurricane by Jordan (1952) and Huges (1952), Palmén and Riehl (1957) obtained the value of $C_{d}$ ranging from $1.1 \times 10^{-3}$ to $2.2 \times 10^{-3}$ for wind speeds of about 6 to $26 \mathrm{~m} / \mathrm{sec}$ (Fig. 9). Miller (1964) obtained the value of $C_{d}$ ranging from $2.4 \times 10^{-3}$ to $3.2 \times 10^{-3}$ (wind speed 30 to $40 \mathrm{~m} / \mathrm{sec}$ ) for Hurricane Hellen, and furthermore he calculated the drag coefficient as a function of wind speed over water for hurricane Donna, which are represented by circle in Fig. 9.

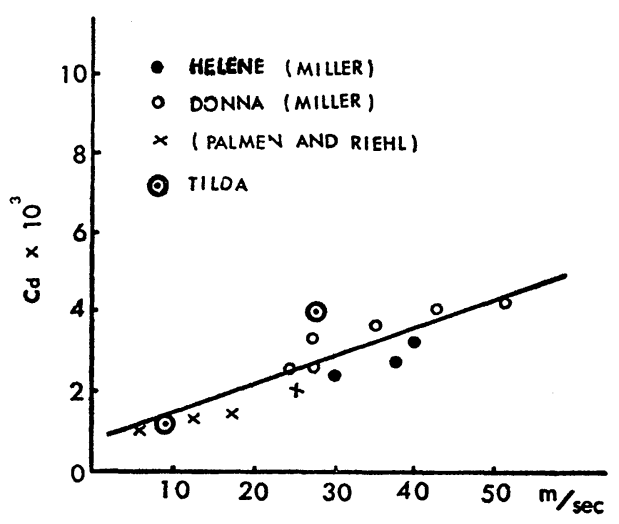

Fig. 9 Drag coefficient as a function of wind speed over ocean surface. 
The values of drag coefficient estimated for typhoon "Tilda" under consideration are plotted by symbol $\odot$ in Fig. 9. As is seen, the present results are fairly accordant to the previous estimations. The estimated value of the drag coefficient will be used for calculating the heat flux from the ocean surface in the following section.

\section{The oceanic heat source and air-sea exchange}

Byers (1959) first suggested the role of warm ocean surface as a heat source for the tropical cyclone. Palmén and Riehl (1957), Malkus and Riehl (1960) and Miller (1964) pointed out that the heat flux from the ocean surface plays an important role in maintaining a tropical cyclone. In a tropical cyclone, pressure is nearly hydrostatic as demonstrated by Haurwitz (1935). So the substantial reduction of the surface pressure is considered to be brought about by tropospheric heating. This heating is due to the release of latent heat in the rain area. Thus given a fixed top, the surface pressure at any point can be determined hydrostatically by the equivalent potential temperature at the surface under the assumption that the vertical temperature profile results from moist adiabatic ascent of the surface air. It is shown by Riehl (1954) that the total heat content of normal tropical air (corresponding to equivalent potential temperature $\left.\left(\theta_{E}\right) 350^{\circ} \mathrm{A}\right)$ which is raised without mixing with surrounding air to the level of zero buoyancy, is insufficient to lower surface pressure substatially below 1000 $\mathrm{mb}$. It follows that the oceanic heat source must exist within the tropical cyclone to permit increase of $\theta_{E}$ of surface air above $350^{\circ} \mathrm{A}$. The heat so gained by the air during its motion toward the center is only a small fraction of that which is possessed by the air originally at the distance of $500 \mathrm{~km}$ or so from the center... Roughly speaking, when the central pressure is as low as 900 $\mathrm{mb}$, the increase of latent heat by oceanic heat source will approach 10 percent and that of sensible heat 3 percent. Neverthless it is this small increment that produce the strong inward warming throughout the troposphere by moist adiabatic ascent and therefore determine the pressure gradient and the magnitude of kinetic energy production.

In order to show actually the important role of oceanic heat source, we make the caluculation of the sensible and latent heat supply over the sea along a trajectory of the air toward the typhoon center and compare them with that over the land surface. The sensible heat supply along a trajectory may be obtained by integration of the equation which expresses the first law of thermodynamics along that,

$$
\Delta Q_{S P}=C_{P}\left(T_{1}-T_{2}\right)+R \bar{T} \ln \left(P_{1} / P_{2}\right)
$$

where $\Delta Q_{S P}(\mathrm{cal} / \mathrm{g})$ is the change in sensible heat content along the trajectory of an air mass, $C_{P}$ is specific heat at constant pressure, $R$ is the gas constant and $T$ is the temperature. Similarly,

$$
\Delta Q_{e} p=L\left(q_{2}-q_{1}\right)
$$

where $\Delta Q_{e} p(\mathrm{cal} / \mathrm{g})$ is the gain in latent heat of an air mass, $q$ is the specific humidity, $L$ the latent heat of condensation. Subscripts 1 and 2

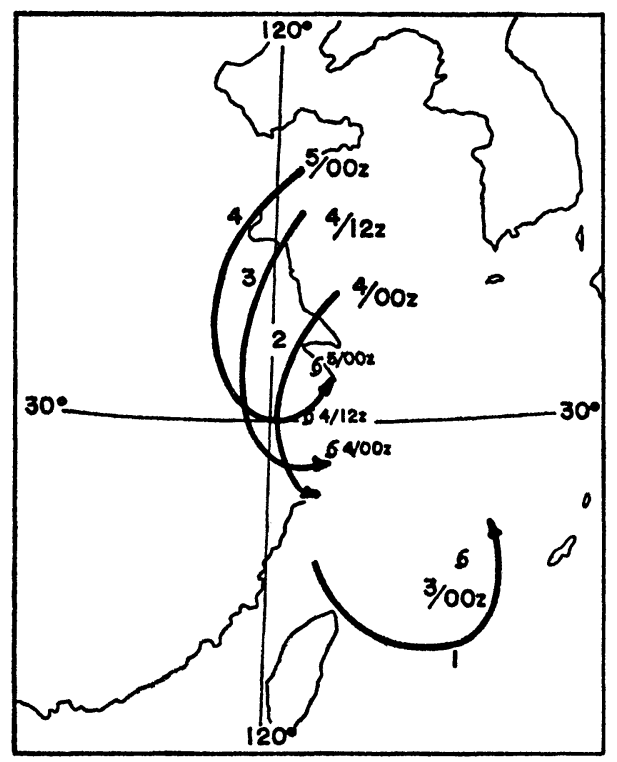

Fig. 10 Trajectories which are used in the calculation of $\Delta Q_{s p}$ and $Q \Delta_{e p}$.

Table 1. The sensible $\left(\Delta Q_{s p}\right)$ and latent $\left(\Delta Q_{e p}\right)$ heat supplies which are acquired by air parcel during the travelling toward the cyclone center along the trajectories described in Fig. 10.

\begin{tabular}{l|c|c|c}
\hline trajectory number & $\Delta Q_{s p}$ & $\Delta Q_{e p}$ & total \\
\hline 1, (over water) & +1.48 & +2.90 & +4.38 \\
2, (over land) & -1.37 & +0.06 & -1.31 \\
3, (over land) & +0.12 & -0.06 & +0.06 \\
4, (over land) & -0.36 & -1.12 & -1.56 \\
\hline
\end{tabular}

Unit; cal/gm 
in (5.1) and (5.2) denote the value at the central and peripheral region of the cyclone respectively.

Four trajectories are constructed for the $3 \mathrm{rd}$ to the 5th of October (Fig. 10) from 3 hourly streamline-isotach analysis, using the method described by Petterssen (1956). Among these four trajectories, one on the 3rd is the trajectory over water, while the remaining three are over land. Over water the increase in both sensible and latent heat along the trajectory are large as expected. Over land an appreciable increase in both sensible and latent heat are not shown, rather the decrease in the latter are indicated (table 1). This estimation indicates that over water, heat supply is very significant, while over land this effect can be negligible. So following analysis we neglect the heat supply from the surface over the land.

The above calculations are made concerning a particular parcel of air. However, it is required to estimate heat and water vapor fluxes per unit area of the underlying surface for the energy budget which will be mentioned in the following section. So we estimated these fluxes using .Jacobs' method.

According to Jacobs' method,

$$
\begin{aligned}
& Q_{s}=\rho C_{h} C_{p}\left(T_{s}-T_{a}\right) \boldsymbol{V}_{0} \\
& Q_{e}=\rho L C_{e}\left(q_{s}-q_{a}\right) \boldsymbol{V}_{0}
\end{aligned}
$$

where $Q_{s}$ and $Q_{e}$ are the sensible and the latent heat supplies per unit area of the surface. $\rho$ is density of air at the surface, $C_{h}$ and $C_{e}$ are dimensionless exchange coefficients for sensible and latent heat respectively, $T_{s}$ is the temperature of underlying surface $T_{a}$ is the temperature of air at the anemometer level, $q_{s}$ is the saturation specific humidty corresponding to $T_{s}, q_{a}$ is the actual specific humidity, $V_{0}$ is the wind speed at anemometer level. Because there is no definite data to show the difference among $C_{h}, C_{e}$ and $C_{d}$, we assume that $C_{h}=C_{e}=C_{d}$, where $C_{d}$ is the drag coefficient which is estimated in the previous section.

In order to estimate the value of $\left(T_{s}-T_{a}\right)$ and $\left(q_{s}-q_{a}\right)$, we must obtain some estimation of sea surface temperature during the passage of the typhoon. Since there are not many ship reports inside the $500-\mathrm{km}$ radius, some extrapolation of the available data is required. For this purpose, we used composit technique for water
Table 2. The sensible $\left(Q_{s}\right)$ and latent $\left(Q_{e}\right)$ heat supplies from the ocean per unit area of the surface, which are calculated by Jacobs' method.

\begin{tabular}{c|c|c|c|c|c}
\hline & 00 GMT & 12 GMT & 4th & 4th & 5 5 th \\
& 12 GMT & 00 GMT \\
\hline$Q_{s}$ & 14.0 & 7.7 & 2.0 & 1.7 & 0.1 \\
$Q_{e}$ & 79.4 & 50.6 & 23.3 & 9.8 & 5.0 \\
$\begin{array}{c}\text { Bowen } \\
\text { Ratio }\end{array}$ & 0.18 & 0.15 & 0.09 & 0.17 & 0.2 \\
\hline \multicolumn{2}{c}{}
\end{tabular}

temperature during a 5-day period (October 1-5) and is averaged at every $5^{\circ}$ latitude-longitude squares. The estimated values of sensible and latent heat fluxes are shown in Table 2.

\section{The balance of heat and water vapor}

We make the calculation of the budget of heat and water vapor for the cylindrical air column with a radius of 5-deg. latitude extending from the surface to the $100 \mathrm{mb}$ level, in two different manner independent of each other. The cylindrical coordinate system used in following analysis has its origin at position of moving typhoon center at each time.

Using the first law of thermodynamics and the continuity relation of water vapor, we obtain

$$
\begin{aligned}
& \frac{C_{p}}{\left(\frac{1000}{p}\right) \frac{R}{C_{p}}}\left\{\left[\frac{\pi r_{1}^{2}}{g} \frac{\partial}{\partial t} \int_{P_{n}}^{P_{n-1}} \bar{\theta} d p\right]+\frac{2 \pi r_{1}}{g}\right. \\
& \quad \times \int_{P_{n}}^{P_{n-1}} \bar{\theta} \bar{v}_{r} d p+\frac{\pi r_{1}^{2}}{g}[\bar{\theta} \bar{w}]_{P_{n}}^{P_{n-1}} \\
& \left.+\frac{\pi r_{1}^{2}}{g}\left[\overline{\theta^{\prime} w^{\prime}}\right]_{P_{n}}^{P_{n-1}}\right\}=\frac{1}{g}\left(\int_{P_{n}}^{P_{n-1}} L P_{r} d p\right. \\
& \left.-\int_{P_{n}}^{P_{n-1}} R_{a} d p\right)
\end{aligned}
$$

and

$$
\begin{aligned}
& \left\{\frac{\pi r_{1}^{2}}{g} \frac{\partial}{\partial t} \int_{P_{n}}^{P_{n-1}} L \bar{q} d p+\frac{2 \pi r_{1}}{g} \int_{P_{n}}^{P_{n-1}} \overline{L q v_{r}} d p\right. \\
& \left.\quad+\frac{\pi r_{1}^{2}}{g}[L \bar{q} \bar{w}]_{P_{n}}^{P_{n-1}}+\frac{\pi r_{1}^{2}}{g}\left[\overline{L q^{\prime} w^{\prime}}\right]_{P_{n}}^{P_{n-1}}\right\} \\
& =\frac{-1}{g} \int_{P_{n}}^{P_{n-1}} L P_{r} d p
\end{aligned}
$$

Here the bar denotes the areal mean of each quantity over the circular with radius $r_{1}$ and the prime the deviation of them from the mean value. The left side of (6.1) can be transformed as 


$$
\begin{aligned}
& \frac{\pi r_{1}^{2}}{g} \int_{P_{n}}^{P_{n-1}} \frac{d}{a t}\left(\overline{C_{p} T}-\overline{\alpha w}\right) d p \\
= & \frac{\pi r_{1}^{2}}{g} \int_{P_{n}}^{P_{n-1}}\left(C_{p} \frac{d \bar{T}}{a t}+\frac{d \bar{\phi}}{a t}-\overline{V_{\nabla} \phi}-\frac{\partial \bar{\phi}}{\partial t}\right) d p
\end{aligned}
$$

The third term in the integral of right side expresses the conversion of potential energy $\phi$ to kinetic energy, which is small compared with other terms by two or three order. And last term is approximately zero because of the assumption of mass balance. So for simplicity we rewrite (6.1) into (6.4)*.

$$
\begin{aligned}
& \frac{\pi r_{1}^{2}}{g}\left\{\frac{\partial}{\partial t} \int_{P_{n}}^{P_{n-1}}\left(\overline{C_{p} T}+\overline{g z}\right) d p+\frac{2 \pi r_{1}}{g}\right. \\
& \quad \times \int_{P_{n}}^{P_{n-1}}\left(\overline{\left.C_{p} T+g z\right) v_{r}} d r+\frac{\pi r_{1}^{2}}{g}\right. \\
& \quad \times\left[\overline{\left(C_{p} T+g z\right) \bar{w}}\right]_{P u}^{P_{n-1}} \\
& \quad+\frac{\pi r_{1}^{2}}{g}\left[\overline{\left.C_{p} T+g z\right)^{\prime} w^{\prime}}\right]_{P_{n}}^{P_{n-1}} \\
& =\frac{1}{g} \int_{P_{n}}^{P_{n-1}} L P_{r} d p-\frac{1}{g} \int_{P_{n}}^{P_{n-1}} R_{a} d p
\end{aligned}
$$

where $\theta$ is the potential temperature, $\alpha$ is specific volume, $P_{r}$ is the rate of condensation, $R_{a}$ is the rate of radiative cooling and $r_{1}(6.4)$ is about $500 \mathrm{~km}$ (5-deg. lat.) The first terms of (6.4) and (6.2) are the local time change of heat (=enthalpy plus potential energy) and water vapor of the cylindrical air column between $P_{n-1}$ and, $P_{n}$ second terms are horizontal transports of heat and water vapor through the vertical wall of the cylinder, the third terms are the difference between the vertical transports of heat and water vapor at level $P_{n-1}$ and $P_{n}$ due to the mean vertical motion and the fourth terms are those due to convective vertical motion respectively. The right side of (6.4) and (6.2) are source or sink terms.

Integrating (6.4) and (6.2) from the surface to the top of the storm, we obtain

$$
\begin{aligned}
& \frac{\pi r_{1}^{2}}{g} \frac{\partial}{\partial t} \int_{100}^{1000} \overline{\left(C_{p} T+g z\right)} d p+\frac{2 \pi r_{1}}{g} \\
& \quad \times \int_{100}^{1000} \overline{\left(C_{p} T+g z\right) v_{r}} d p=\frac{1}{g} \int_{100}^{1000} L P_{r} d p \\
& \quad+\pi r_{1}^{2} Q_{s}-\frac{1}{g} \int_{100}^{1000} R_{a} d p
\end{aligned}
$$

* In the present analysis, actually we used potential temperature to calculate the heat budget (equation (6.4)). and

$$
\begin{gathered}
\frac{\pi r_{1}^{2}}{g} \frac{\partial}{\partial t} \int_{100}^{1000} L \bar{q} d p+\frac{2 \pi r_{1}}{g} \int \overline{L q v_{r}} d p \\
=-\frac{1}{g} \int_{100}^{1000} L P_{r} d p+\pi r_{1}^{2} Q_{e}
\end{gathered}
$$

where

$$
\frac{1}{g}\left[\left(\overline{\left(C_{p} T+g z\right)^{\prime} w^{\prime}}\right]_{P=1000}=Q_{s}\right.
$$

and

$$
\frac{1}{g}\left[\overline{\left(L q^{\prime} w^{\prime}\right)}\right]_{P=1000}=Q_{e}
$$

Here it is assumed that the mean vertical $p$ velocity vanishes at the surface and the top (100 $\mathrm{mb}$ ). Furthermore we assume that the eddy transports of sensible and latent heat are zero at the top level and those at the surface are $Q_{s}$ and $Q_{e}$ which were estimated in previous section. In the present analysis, there is no information about radiation. However in the tropical cyclone the main radiational surface is thought to be the top of the outflow overcast, which may act as a black body radiator in the first approximation. Cloud photographs obtained by weather reconnaissance flight observation revealed that the temperature at the top the thick cirrostratus is about $-40^{\circ} \mathrm{C}-60^{\circ} \mathrm{C}$ (Riehl and Malkus (1961)). So the radiative cooling rate is about $0.24-0.17$ ly/min, which corresponds to a mean tropospheric

\begin{tabular}{|c|c|c|c|c|c|}
\hline & $00 \stackrel{3 \mathrm{rd}}{\mathrm{GM}}$ & $12 \stackrel{3 \mathrm{rd}}{\mathrm{GMT}}$ & 00 GMT & 12 GMT & 00 GMT \\
\hline $\begin{array}{c}\int_{100}^{1000} L P d p \\
(E q .6 .3)\end{array}$ & 4. 3 & 4.5 & 3.8 & 2.2 & 1.5 \\
\hline $\begin{array}{c}\int_{100}^{1000} L P d p \\
(E q .6 .4)\end{array}$ & 3.6 & 3.2 & 2.4 & 1.7 & 1.4 \\
\hline
\end{tabular}
cooling of $1^{\circ} \mathrm{C} /$ day. These values are rather small compared with latent heat released by condensation of water vapor. Thus we will neglect the radiative effect.

The results of independent estimation of $\left(\int_{100}^{1000} L P_{r} d p\right)$ using (6.5) and (6.6) show a fairly

Table 3. The released latent heat due to the condensation of water vapor for the entire air column extending from the surface to the top level, which are calculated from the first law of thermodunamics and the continuity relation of water vapor independently of each other.

Unit; cal/gm. $12 \mathrm{hr}$ 
good coincidence with each other (table 3), therefore the main heat source of the system is shown to be the released latent heat of condensation. Thus the decrease of the heat of condensation $\left(\int_{100}^{1000} L P_{r} d p\right)$ during the decay of the typhoon suggests the collapse of the warm core mainly due to the decrease of condensation.

\section{Consideration on vertical heat flux and the role of hot tower}

In order to see the time change in the convective activity within the typhoon region during the period of decay, we must calculate the convective vertical transport of heat and water vapor (the fourth terms of left side in (6.2) and (6.4)) and the rate of condensation in each layer $\left(\int_{P_{n}}^{P_{n-1}} L P_{r} d p\right.$ in (6.2) and (6.4)). We can estimate these terms not directly, but as residuals as follows,

$$
\begin{aligned}
Q_{1}= & \frac{1}{g} \int_{P_{n}}^{P_{n-1}} L P_{r} d p-\frac{\pi r_{1}^{2}}{g}\left[\overline{\left(C_{p} T+g z\right)^{\prime} w^{\prime}}\right]_{P_{n}}^{P_{n-1}} \\
= & \frac{\pi r_{1}^{2}}{g} \frac{\partial}{\partial t} \int \overline{\left(C_{p} T+g z\right)} d p+\frac{2 \pi r_{1}}{g} \\
& \times \int_{P_{n}}^{P_{n-1}} \overline{\left(C_{p} T+g z\right)} v_{r} d p+\frac{\pi r_{1}^{2}}{g} \\
& \times\left[\overline{\left(C_{p} T+g z\right)} \bar{w}\right]_{P_{n}}^{P_{n-1}}
\end{aligned}
$$

and

$$
\begin{aligned}
Q_{2}= & \frac{1}{g} \int_{P_{n}}^{P_{n-1}} L P_{r} d p+\frac{\pi r_{1}^{2}}{g}\left[\overline{L q^{\prime} w^{\prime}}\right]_{P_{n}}^{P_{n-1}} \\
= & -\frac{\pi r_{1}^{2}}{g} \frac{\partial}{\partial t} \int_{P_{n}}^{P_{n-1}}(\bar{L} \bar{q}) d p+\frac{2 \pi r_{1}}{g} \\
& \times \int_{P_{n}}^{P_{n-1}} L \overline{q v_{r}} d p+\frac{\pi r_{1}^{2}}{g}[L \bar{q} \bar{w}]_{P_{n}}^{P_{n-1}}
\end{aligned}
$$

In the same way as in the previous section, the vertical transport of sensible and latent heat from the surface are assumed,

$$
\begin{aligned}
& \frac{1}{g}\left[\overline{\left(C_{p} T+g z\right)^{\prime} w^{\prime}}\right]_{P=1000}=Q_{s} \\
& \frac{1}{g}\left[\left(L \overline{\left.q^{\prime} w^{\prime}\right)}\right]_{P=1000}=Q_{e}\right.
\end{aligned}
$$

Time section of the vertical distributions of $Q_{1}$ and $Q_{2}$ are shown in Fig. 11. This figure shows that both $Q_{1}$ and $Q_{2}$ decrease as the typhoon decays. This indicates that the libera-

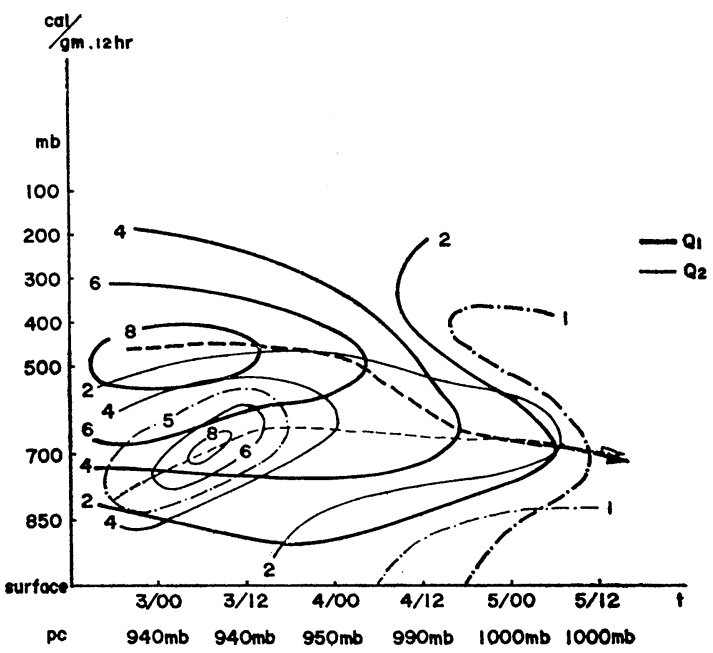

Fig. 11 Vertical time section for the heat analysis from 0000 GMT 3 October to 1200 GMT 5. Thick solid lines indicate, $Q_{1}$, and thin solid lines $Q_{2}$. Thick and thin dashed lines indicate the level of maximum amount of $Q_{1}$ and $Q_{2}$ respectively.

tion of latent heat is a dominant factor for the destruction of warm core. Note that the layer of maximum amount of $Q_{1}$ exists at about the $450 \mathrm{mb}$ level on the $3 \mathrm{rd}$ of October, whereas of the layer of maximum $Q_{2}$ is found at about the $700 \mathrm{mb}$ level. As the typhoon decays, the layer of maximum amount of $Q_{1}$ lowers to the $850 \mathrm{mb}$ level and coincides with the layer of the maximum $Q_{2}$.

It is interesting to note here a datailed analysis of the formation of a typhoon "Doris" by Yanai (1961). It was indicated in the formative stage of the typhoon main layer of liberation of latent heat calculated from water balance in the same manner as $Q_{2}$ in the present analysis was found mainly below the principal layer of heat source calculated from the heat balance in the same manner as $Q_{1}$.

This salient phenomena that in the formative and mature stage of a tropical cyclone, the significant warming tends to take place in the upper layer above the layer in which condensation of water vapor mainly occures, suggests the existence of upward fluxes of sensible and latent heat by small scale convections which occupy very small percentage area of the typhoon region. When cumulonimbi are active, stronger upward heat transport can be expected. Thus 

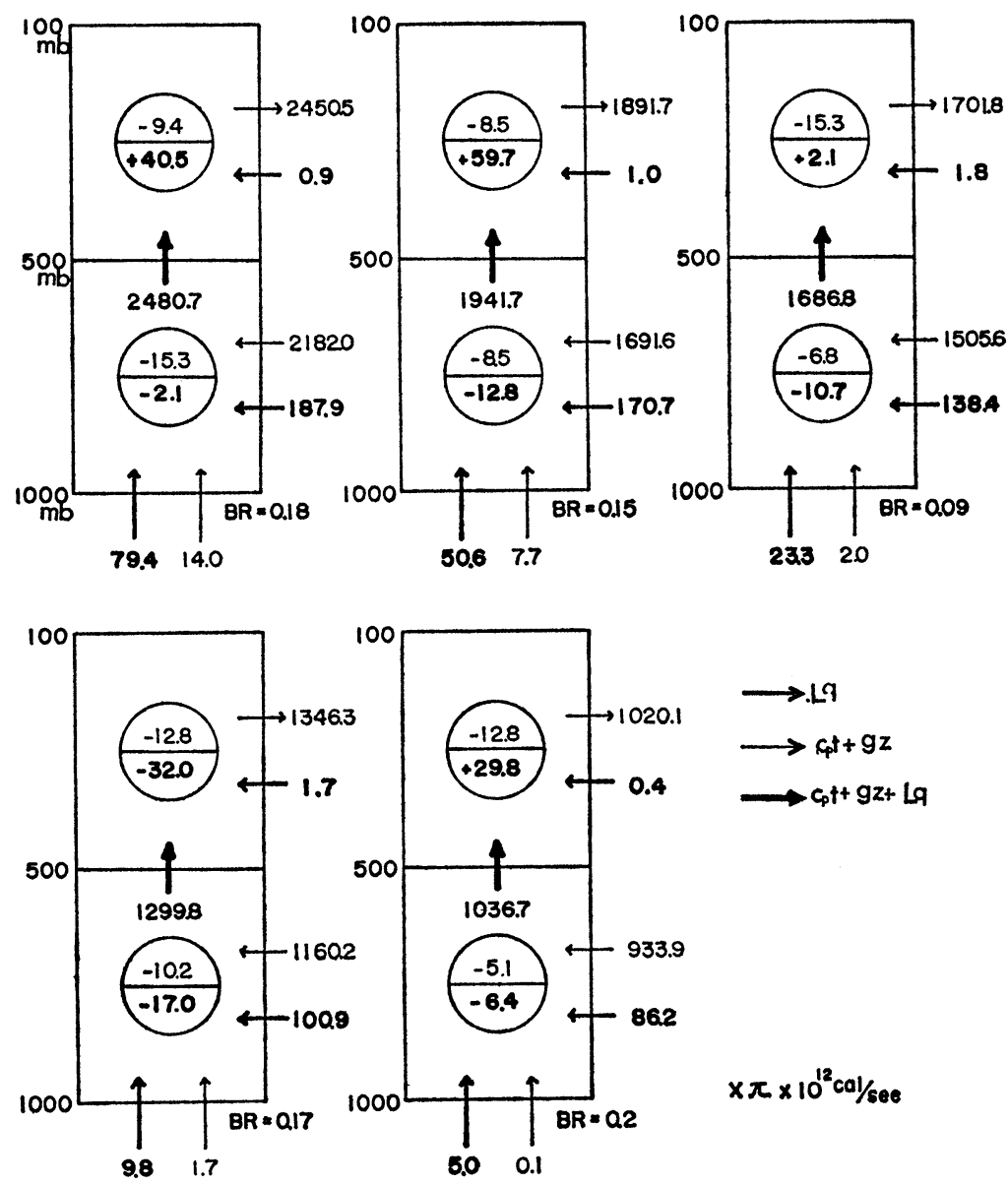

Fig. 12 The heat budget diagram. Thin and thick arrows indicate the trastport of sensible and water vapor respectively, and number in circles denote local time change of them. Black vertical arrows at the $500 \mathrm{mb}$ level denote $H_{500}$. $B R$ is Bowen's ratio.

the difference between the height of these two layers is considered to be a kind of the index for the activity of convection. Subtracting (7.2) from (7.1), one finds

$$
Q_{1}-Q_{2}=-\frac{\pi r_{1}^{2}}{g}\left[\overline{\left(C_{p} T+g z+L q\right)^{\prime} w^{\prime}}\right]_{P_{n}}^{P_{n-1}}
$$

Thus $\left(Q_{1}-Q_{2}\right)$ expresses vertical divergence of the convective upward transport of sensible and latent heat between $P_{n}$ and $P_{n-1}$. So if we note that in the present analysis, these two layers approach each other with time, we may conclude that the activity of convection within the typhoon region weakens gradually as the typhoon decays.

Next, carrying out the subtraction of (7.2) from
(7.1) to eliminate $L P_{r}$ term, we get

$$
\begin{gathered}
\pi r_{1}^{2} \frac{\partial}{\partial t} \int_{P_{n}}^{P_{n-1}} \bar{Q} d p+2 \pi r_{1} \int_{P_{n}}^{P_{n-1}} \overline{Q v_{r}} d p=-\pi r_{1}^{2} \\
\times\left[\bar{Q} \bar{w}+\overline{Q^{\prime} w^{\prime}}\right]_{P_{n}}^{P_{n-1}}
\end{gathered}
$$

where $Q$ is the total heat content $\left(=C_{p} T+g Z\right.$ $+L q)$.

Integrating (7.6) from the surface to the 500 mb level, we can obtain the vertical flux of total heat through the $500 \mathrm{mb}$ level for the three days as follows,

$$
H_{500}=\left[\pi r_{1}^{2}\left(\bar{Q} \bar{w}+\overline{Q^{\prime} w^{\prime}}\right)\right]_{P=500}
$$




$$
\begin{gathered}
=\pi r_{1}{ }^{2} \frac{\partial}{\partial t} \int_{1000}^{500} \bar{Q} d p+2 \pi r_{1} \int_{1000}^{500} \overline{Q v_{r}} d p+\pi r_{1}{ }^{2} Q_{s} \\
+\pi r_{1}{ }^{2} Q_{e}
\end{gathered}
$$

The results are indicated by thick vertical arrow in Fig. 12. Thus we determine $H_{500}$ from the total heat budget for lower layer i. e. below the $500 \mathrm{mb}$ level. This is due to that the data is much denser in lower layer than in upper layer.

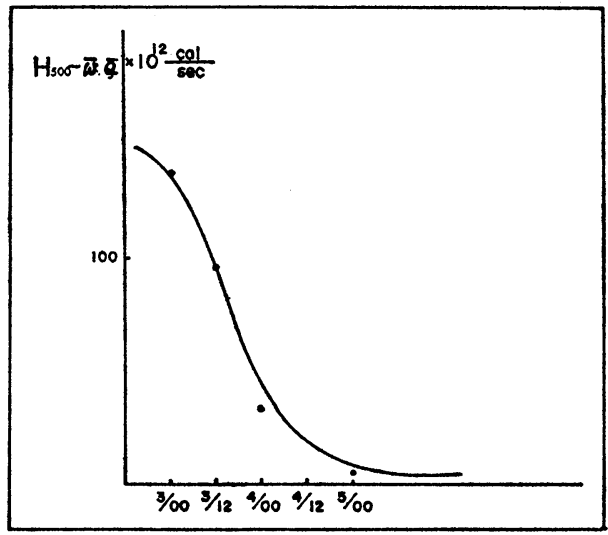

Fig. 13 Time change in the difference between $H_{500}$ and $\bar{Q} \bar{w}$. abscissa denotes dating.

Now let us compare $H_{500}$ with vertical flux of total heat by mean vertical motion $\bar{Q} \bar{w}$. The value of $\left(H_{500}-\bar{Q} \bar{w}\right)$ for these three days is shown in Fig. 13. It is very large on the 3rd of October when the typhoon was still in the mature stage, while it decrease considerably as the typhoon decays. This suggests that in the mature stage the heat balance can never be accomplished without vertical transport due to convective eddy motion, while in the final decaying stage heat balance is almost accomplished by the vertical transport due to mean vertical motion and no strong convective heat transport is required.

In order to make clear the convective transport described above, as proposed by Riehl and Malkus $(1958,1961)$, we assume that the low level air with high heat content rises in active cumulonimbus towers to the upper levels without mixing with surrounding air. Several ascent curves in the central part of the typhoon shows that the condensation level exists near the $900 \mathrm{mb}$ level. However, the data were so scarce at this level that we must adopt the $850 \mathrm{mb}$ level as cloud base. And we take the mean equivalent potential temperature within $300 \mathrm{~km}$ radius at the $850 \mathrm{mb}$ level as the representative heat content possessed by the air rising in active cumulonimbus towers within the typhoon.

Riehl and Malkus $(1958,1961)$ persisted that in an equatrial trough zone, the heat balance can never be accomplished without considering the mechanism of counter gradient heat flux; the low level air must be raised to the upper levels undilutely. They applied the hot tower hypothesis to the heat budget analysis of Hurricane "Daisy" (1961). Although the undilute ascent above mentioned is considered to occur in extremely restricted region of rapidly rising cumulonimbus towers, the ascent rate in cumulonimbi is very large. Therefore the role of cumulonimbus towers in the heat balance may be very significant.

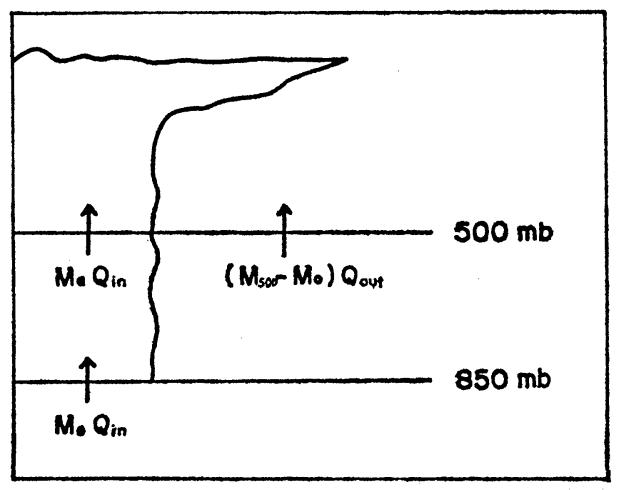

Fig. 14 Mechanism of vertical heat fluxes

In the present analysis, we separate the vertical heat flux by cumulonimbus towers from that by diffusion probably due to small clouds.

The vertical mass transport through the 500 $\mathrm{mb}$ level $\left.M_{500}(\mathrm{gm} / \mathrm{sec})=\pi r_{1}^{2} \bar{w} / g\right)$ may be divided as follows,

$$
M_{500}=M_{0}+\left(M_{500}-M_{0}\right)
$$

where $M_{0}(\mathrm{gm} / \mathrm{sec})$ denotes the mass flux through the $500 \mathrm{mb}$ level inside of hot towers, and $\left(M_{500}\right.$ $\left.-M_{0}\right)(\mathrm{gm} / \mathrm{sec})$ the mass flux through the same level outside of hot towers.

Let $Q_{I N}$ denote the heat content of the air with characteristics of the subcloud layers and Qour the heat content at the $500 \mathrm{mb}$ level outside of hot tower. If asending mass in hot towers has the heat content $Q_{I N}$ and that outside of the hot tower has QouT, the vertical heat flux $H_{500}$ through the $500 \mathrm{mb}$ level is expressed as follows 


$$
H_{500}=M_{0} Q_{I N}+\left(M_{500}-M_{0}\right) M_{O U T}
$$

Here we take the $850 \mathrm{mb}$ level as the cloud base and the mean equivalent potential temperature at the level within the circular area of $3 \mathrm{deg}$. latitude radius as $Q_{I N}$ and that at the $500 \mathrm{mb}$ level within the circular area of $5 \mathrm{deg}$. latitude radius as QouT. Strictly speaking we must take the representative value of heat content outside of hot tower as QouT. However, the percentage of the area which is occupied by hot tower is quite small. So the difference between thses two value may be negligible.

Using the continuity relation of mass and heat we can solve (7.8) and (7.9) for $M_{0}$.

$$
M_{0}=\left(H_{500}-Q_{\text {OUT }} M_{500}\right) /\left(Q_{I N}-Q_{\text {ovT }}\right)
$$

Table 4. Each term in Eq. (7.10) to determine $M_{0}$ (mass transport through the $500 \mathrm{mb}$ level inside of hot towers) and percent of heat transport by hot towers aginst the entire heat transport required to

\begin{tabular}{|c|c|c|c|c|c|}
\hline & $\begin{array}{c}\text { 3rd } \\
00 \mathrm{GMT}\end{array}$ & $12 \stackrel{3 \mathrm{rd}}{\mathrm{GMT}}$ & 4th & 12 GMT & $\begin{array}{l}5 \text { th } \\
00 \mathrm{GT}\end{array}$ \\
\hline $\begin{array}{c}M_{500} \\
(\mathrm{gm} / \mathrm{sec})\end{array}$ & $\mid \begin{array}{c}29.0 \\
\times 10^{12} \times \pi\end{array}$ & $\mid \begin{array}{c}22.8 \\
\times 10^{12} \times \pi\end{array}$ & $\begin{array}{c}20.3 \\
\times 10^{12} \times \pi\end{array}$ & $\tau \mid \begin{array}{c}16.6 \\
\times 10^{12} \times \pi\end{array}$ & $\begin{array}{c}13.2 \\
\times 10^{12} \times \pi\end{array}$ \\
\hline $\begin{array}{c}Q_{I_{N}} \\
(\mathrm{cal} / \mathrm{gm})\end{array}$ & 87.0 & 85.3 & 83.8 & 82. 2 & 81.2 \\
\hline $\begin{array}{c}Q_{O U T} \\
(\mathrm{cal} / \mathrm{gm})\end{array}$ & 80.8 & 81.0 & 81.6 & 78.2 & 78.2 \\
\hline $\begin{array}{c}M_{0} \\
(\mathrm{gm} / \mathrm{sec})\end{array}$ & $\begin{array}{c}22.0 \\
\times 10^{12} \times \pi\end{array}$ & $\mid \begin{array}{c}21.2 \\
\times 10^{12} \times \pi\end{array}$ & $\begin{array}{c}13.8 \\
\times 10^{12} \times \pi\end{array}$ & $\tau \times 10^{12} \times \pi$ & 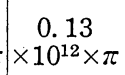 \\
\hline $\begin{array}{l}Q_{I N} M_{O U T} / \\
H_{500}(\%)\end{array}$ & 77.2 & 93.1 & 68.6 & 7.6 & 1.0 \\
\hline
\end{tabular}
achieve heat balance.

The estimations of $M_{0}$ and percentage of $H_{500}$ to be carried by hot towers are shown in table 4 . As is shown in table 4, the hot tower plays a significant role in the heat balance of typhoon in mature stage, while it becomes unimportant as the typhoon decays.

We may now compare the mass flux requirement in hot towers $\left(M_{0}\right)$ with vertical velocity in cumulonimbus computed by kinematic method in the case of Hurricane "Daisy" based on the cloud observation obtained by penetrating flights. In the case of "Daisy" the ascent rate at the 237 $\mathrm{mb}$ level of a buoyant element of $4 \mathrm{~km}$ diameter was $12 \mathrm{~m} / \mathrm{sec}$. Assuming the area occupied by hot towers to be one percent in our analysis, the ascent rate in hot towers at the $500 \mathrm{mb}$ level will be 7-8 $\mathrm{m} / \mathrm{sec}$ for the mature stage, and 1.$0.5 \mathrm{~m} / \mathrm{sec}$ for the final stage. Furthermore if we take $10 \mathrm{~m} / \mathrm{sec}$ as a typical ascent rate in hot towers at the $500 \mathrm{mb}$ level and $0.65 \times 10^{-3} \mathrm{~g} / \mathrm{cm}^{3}$ as the mean density of air at the same level, the area occupied by hot towers will be one percent or so for the mature stage. Riehl and Malkus (1961) and Malkus (1959) indicated from the photographic analysis of Hurricane Daisy that the area occupied by hot towers were a few percent of the area within $100 n$-mile radius for the mature stage, so which is obtained in the present analysis seems to be reasonable.

\section{Relation between the vertical distribution of liberation of latent heat and the warm core of the typhoon}

We shall calculate vertical distribution of liberation of latent heat using $M_{0}$ which was estimated in the previous section. The cylindrical air column of the radius $500 \mathrm{~km}$ is divided into two parts; the upper part (from the $500 \mathrm{mb}$ level to the $100 \mathrm{mb}$ level) and the lower part (from the surface to the $500 \mathrm{mb}$ level) and we calculate the liberation of latent heat for each part using the continuity relation of water vapor as follows,

$$
\begin{aligned}
L P_{H}= & \frac{1}{g} \int_{100}^{500} L P_{r} d p=-\frac{\pi r_{1}^{2}}{g} L \frac{\partial}{\partial t} \int_{100}^{500} \bar{q} d p \\
& -L \frac{2 \pi r_{1}}{g} \int_{100}^{500} \overline{q v_{r}} d p-L\left[\left(q_{0} M_{0}\right.\right. \\
& \left.\left.+\bar{q}\left(M_{500}-M_{0}\right)\right)\right]_{P=500}
\end{aligned}
$$

and

$$
\begin{aligned}
L P_{L}= & \frac{1}{g} \int_{500}^{1000} L P_{r} d p=-L \frac{\pi r_{1}^{2}}{g} \frac{\partial}{\partial t} \int_{500}^{1000} \bar{q} d p \\
& -L \frac{2 \pi r_{1}}{g} \int_{500}^{1000} \overline{q v_{r}} d p+L\left[\left(q_{0} M_{0}\right.\right. \\
& \left.\left.+\bar{q}\left(M_{500}-M_{0}\right)\right)\right]_{P=500}+\pi r_{1}^{2} Q_{e}
\end{aligned}
$$

where $P_{H}$ and $P_{L}$ are the amount of condensed water in the upper and lower layers respectively, $\bar{q}$ is the representative value of specific humidity at the $500 \mathrm{mb}$ level outside of hot towers which is estimated by mean specific humidity within $500 \mathrm{~km}$ radius and $q_{0}$ is specific humidity at the same level inside of hot towers. Assuming the saturation adiabatic process in hot towers $q_{0}$ would be the saturation specific humidity corresponding to the temperature at the $500 \mathrm{mb}$ 


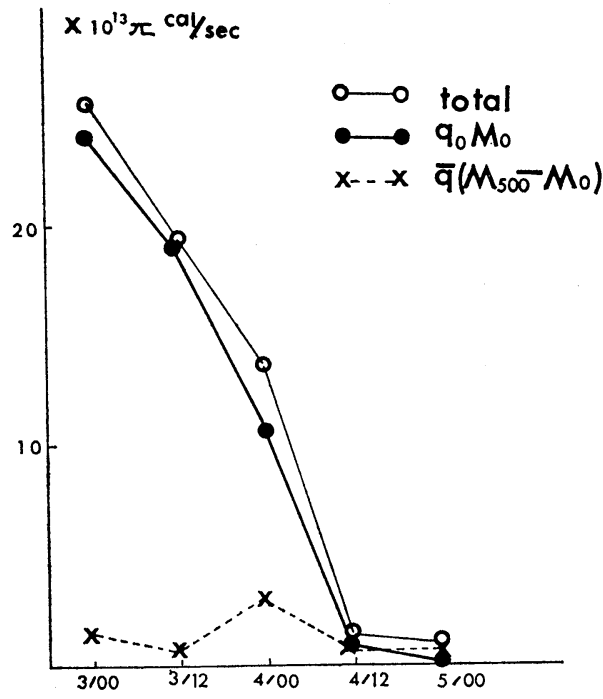

Fig. 15 Time changes in upward transport of water vapor through the $500 \mathrm{mb}$ level.

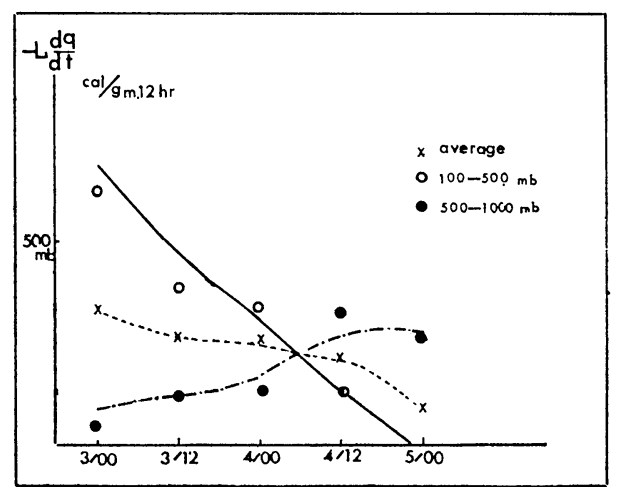

Fig. 16 Vertical distribution of the liberation of latent heat.

level which is determined by mean temperature within the circular area of $300 \mathrm{~km}$ radius at cloud base $(=850 \mathrm{mb}$ level). The mass which passes through the $500 \mathrm{mb}$ level outside of hot towers $\left(M_{500}-M_{0}\right)$ possesses specific humidity $q$, while the mass which passes through the same level inside of hot towers $\left(M_{0}\right)$ possesses $q_{0}$. Thus, upward transport of water vapor through the 500 $\mathrm{mb}$ level becomes the sum of $q_{0} M_{0}$ and $q\left(M_{500}\right.$ $-M_{0}$ ), which are shown in Fig. 15.

Using (8.1) and (8.2), we calculated $L P_{H}$ and $L P_{L}$ for three days under consideration (Fig. 16). It is shown in Fig. 16 that the average liberation of latent heat over the entire air column decreases gradually with time as is expected. It is shown, however, that $L P_{H}$ (the liberation of latent heat

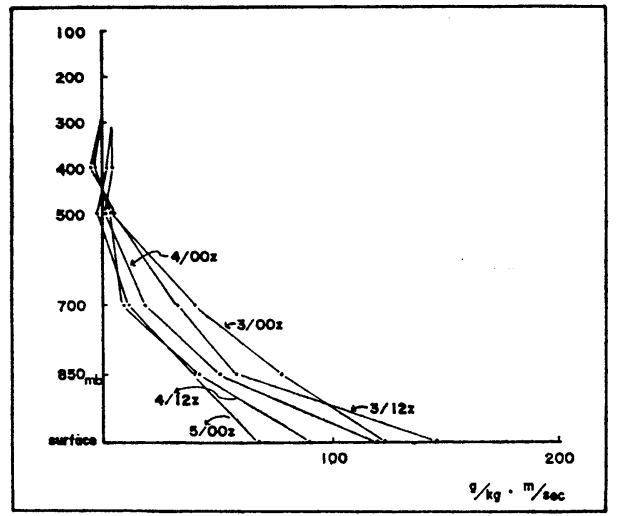

Fig. 17 Horizontal transport of water vapor through the vertical wall with 5-deg. radius.

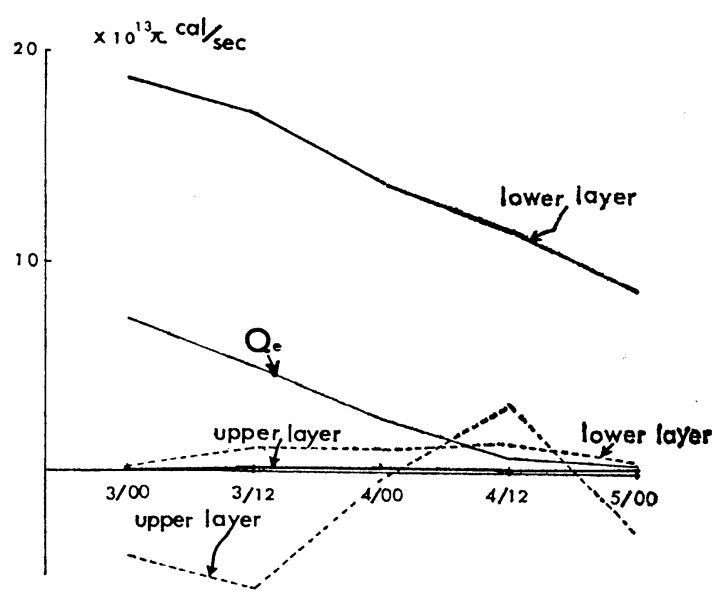

Fig. 18 Horizontal transrport of water vapor through the vertical wall with 5-deg. radius in upper and lower layers (thick solid lines), local time change of them in each layer (dashed lines), and $Q_{e}$ (thin solid lines).

above the $500 \mathrm{mb}$ level) decreases very rapidly, while $L P_{L}$ (that below the $500 \mathrm{mb}$ level) increases gradually.

Because high cumulonimbus towers seems to be the main source of latent heat liberation above the $500 \mathrm{mb}$ leve!, the distinct decrease in $L P_{H}$ suggests that the activity of these high cumulonimbus weakens very rapidly as the typhoon decays. Below the $500 \mathrm{mb}$ level, smaller clouds may contribute to the warming in the lower layer. Therefore the increase of $L P_{L}$ and the decrease of $L P_{H}$ suggest that high cumulonimbus towers diminished into small diffusive clouds.

Finally, we show in Fig. 17 the horizontal 
transport of water vapor through the vertical wall of the cylinder with $500 \mathrm{~km}$ radius. It is clear that the horizontal transport decreases consideravly in the lower layer during the period of the decaying. In order to make clear the order of each term concerning to the budget calculation of water vapor for the whole air column, we show in Fig. 18 the local time change of mean specific humidity in the column and the horizontal transport of water vapor, which are divided into the upper and the lower layers, with water vapor supply from the ocean $Q_{e}$. In the budget calculation, the horizontal transport of water vapor in the lower layer is the most dominant factor, while that in the upper layer was quite negligible during the whole period under consideration.

In the mature satge, the most part of water vapor which is supplied by the horizontal transport in the lower layer is carried to the upper layer through hot towers (c. f. Fig. 15 and Fig. 18), and releases latent heat which contributes to the warming of the upper layer. For the decaying stage the remarkable decrease in the vertical transport of water vapor in hot towers is accompanied with the decrease of the horizontal transport of water vapor in the lower layer. So far as the budget calculation is concerned, we may conclude the water vapor supply through the inflow layer plays the most significant role to determine the activity of high cumulonimbi within the typhoon region, and thus the maintenance of of the typhoon.

\section{Conclusion}

In the present analysis, it is noted that the warm core thermal structre of typhoon "Tilda" is modified considerably as the typhoon decays. This modification appears to be related to the weakening of the activity of convection within the typhoon region. Two independent estimations of released latent heat, using the continuity relation of water vapor and the first law of thermodynamics, show clearly weakening of the convective heat transport, which is considered to be accompanied with the weakening of the activity of the convection within the typhoon region for its decaying stage.

Introducing the hot tower hypothesis, we determine the vertical transport of water vapor due to convective motion for the period of Decay and estimate the vertical distribution of the liberation of latent heat. On the basis of this estimation it is shown the liberation of latent heat in the upper layer decreases very rapidly as the typhoon decays, while that in the lower layer increases gradually. Since high cumulonimbi may be the main source of latent heat in the upper layer, the remarkable decrease of heat liberation in the upper layer suggests that the active cumulonimbi diminish very rapidly during the decaying stage. Thus we may conclude that the diminution of these high cumulonimbi plays a most significant role on the destruction of warm core and hence the decaying of the typhoon.

Finally, it is shown on the basis of the budget calculation of water vapor that the horizontal transport of water vapor through the inflow layer is the most dominant factor to determine the activity of high cumulonimbus towers.

\section{Acknowledgements}

The auther wishes to express her thanks to Dr. T. Asai of Kyoto University, and Dr. M. Yanai of Tokyo University, for their stimulating guidances and discussions. Sincere thanks are also due to Dr. K. Suda, chief of Typhoon Reseach Laboratory of Meteorological Institute, Mr. K. Watanabe of the same laboratory and Mr. S. Kubota and Dr. N. Saiti of Japan Meteorological Agency, for their helpful discussion and suggession. Finally she is also inbeted to Mrs. C. Yata for drafting.

\section{References}

Byers, H.R., 1944: General Meteorology. McGraw-Hill Book Co., New York, 645 pp.

Haurwitz, B., 1935: The hight of tropical cyclones and of the 'eye' of the storm, Mon. Wea. Rev. 63, 45-49.

Hubert, L., 1955: Frictional filling of hurricanes. Bull. Amer. meteor. Soc., 36, 440-445.

Hughes, L.A., 1952: On the low level wind structure of tropical cyclones. J. Meteor. 9, 422-428.

Izawa, T., 1964: On the mean structure of typhoons. Typhoon Res. Lab. Tech. Note 2, 47 pp.

Jacobs, W.C., 1942: On the energy exchange between sea and atmosphere. J. Marine Res. 5, 37-66.

Jordan, E., 1952: An observational study for the upper wind circulation around tropical storm. $J$. Meteor., 9, 340-346.

Kasahara, A., 1955: A note on the vertical structure of the pressure and temperature fields in a typhoon. J. meteor. Soc. Japan, 31, 22-35.

Malkus, J.S., 1959: Recent development in studies on penetrative convection and application to hurricane 
cumulonimbus towers. Cumulous Dynamics First Conf. on Cumulous Convection, Wentworth New Hampshire 65-84.

and energy transformation in steady state hurricanes. Tellus 12, 1-21.

Miller, B.I., 1958: The three-dimentional wind structure around a tropical cyclones. National Hurricane Research Project, No. 15, 41 pp.

- 1964: On the filling of hurricane Donna over land. Mon. Wea. Rev. 92, 389-406.

Palmén, E., 1958: Vertical circulation and release of kinetic energy during the development of hurricane Hazel into an extratropical storm. Tellus, 10, 1-23.

- and H., Riehl, 1957: Budget of angular momentum and energy in tropical cyclones. $J$. Meteor. 14, 150-159.

Petterssen, S., 1956: Weather analysis and forcasting. Second ed., 1, MacGraw-Hill Book Co., 200 PP.

Riehl, H., 1954: Tropical Meteorology. McGraw-Hill Book Co., 392 pp.

, 1963: Some relation between wind and thermal structure of steady state hurricanes, $J$. atmos. sci., 20, 276-287.

- , and J.S. Malkus,, 1958: On the heat balance in equatorial trough zone. Geophisica, 6, 503-538.

hurricane Daisy, 1958. Tellus 13, 181-213

Riehl, H., T.C. Yeh, J.S. Malkus, and N.E. LaSeur, 1951: The northeast trade of the Pacific Ocean. Qurt.J. Roy. meteor. Soc., 77 589-626.

Sverdrup, H.UU., 1957: Oceanography. Handbuch der physik Springer-Verlage, Berlin, 608-670.

Wilson, B.W., 1960: Note on surface wind stress over water at low and high wind speed. J. Geophys. Res. 65. 3377-3382.

Yanai, M., 1958: On the change in thermal and wind structure in a decaying typhoon. J. meteor. Soc. Japan, 36, 141-155.

- 1961: A detailed analysis of typhoon formation, J. meteor. Soc. Japan., 39 187-214.

- 1963: A comment on the creation of warm core in incipient tropical cyclone, J. meteor, Soc. Japan, 41, 183-187.

\section{台風の衰弱機構について}

\section{和田美鈴 \\ 気象研究所 台風研究部}

台風の衰弱機構を解明するため，1961年10月中国大陸に上陸し急速に衰弱した台風6123号 (Tilda) の資料を用い， 定量的解析を行った.

この台風の衰弱期において，上層の warm core 型の温度場は著しく变型する．台風の運動エネルギーを生成する ためには, warm core 型の温度場が維持されねばならないのであるからこの warm core の前壊は, 台風の衰弱の 大きな要因であると考えられる，台風を含む気柱について計算した凝結の潜熱の解放量は，温度場の変形に伴い， 減少する。これより warm core の崩壊は, 台風域内の対流活動の消長と密接に関連していると推定される.

この解析の主たる目的は，上記の warm core の崩壊と台風域内の対流活動の 消長との関係を解明することであ る.

このため，熱力学第一法則と水蒸気の連続関係をそれぞれ独立に用い，熱及び水蒸気の収支を計算し，衰弱期に おいては，熱及び水蒸気の対流による上方輸送が著しく減少していく事を確認した。

次に潜熱の解放の垂直分布を決定しようと試みた。この解析により，上層（500 mb 以上）の解放量が warm core の崩壊に伴い，著しく減少する事が注目された，上層に於ける主たる熱源は，hot tower と呼ばれる非常に背の高い 積乱雲であると想定されるので, この結果は, 衰弱期においては, この積乱雲が急速に減少し，その結果 warm core を維持する事が不可能となることを示するのと考えられる.

最後にこの積乱雲の活動の消長が，下層の流入層における水蒸気の移流により支配されている事を示す. 